\title{
Theoretical study on the detailed repair of O6-methyl guanine to guanine by cysteine
}

\author{
ALI EBRAHIMI*, MOSTAFA HABIBI-KHORASANI, SHIVA REZAZADEH, ROYA BEHAZIN \\ and ABOLFAZL AZIZI \\ Department of Chemistry, University of Sistan and Baluchestan, P.O. Box 98135-674, Zahedan, Iran \\ e-mail: ebrahimi@chem.usb.ac.ir
}

MS received 8 October 2013; revised 17 May 2014; accepted 29 May 2014

\begin{abstract}
The repair process of O6-methylguanine (O6mG) by cysteine (Cys145) has been studied using the quantum mechanical calculations in the presence of solvent water molecules and also using the polarizable continuum model (PCM). The proton transfer from Cys 145 to $\mathrm{O} 6 \mathrm{mG}$, directly and mediated by bridged water molecules, has been considered to investigate the role and the sequence of the proton transfer on the repair process. In both models, the energy barrier of the methyl transfer is reduced when the proton is initially transferred from O6mG to Cys145. In addition, the protonation of $\mathrm{N} 3$ and $\mathrm{N} 7$ sites of O6mG in the acidic environment facilitates the repair process. Results of this study help to understand repair mechanisms of damaged DNA bases better on the basis of proton transfer between that and nucleic acids.
\end{abstract}

Keywords. O6-alkylguanine-DNA alkyltransferase; DNA repair; DNA damage; Mispair; methylating agents.

\section{Introduction}

Living cells are constantly exposed to both exogenous (chemical pollutants and UV radiation) and endogenous (the normal metabolic byproducts, especially in the oxidative deamination process) sources of DNA damaging agents. ${ }^{1-6}$ Methylating agents which lead to a wide range of DNA damage such as aging, chronic inflammatory diseases, mutation, cancer, Alzheimer's and Parkinson's diseases ${ }^{7-10}$ can be located on the endocylic nitrogen and exocyclic oxygen atoms of DNA bases (N7, N3 and $\mathrm{O} 6$ in the purines and $\mathrm{O} 2, \mathrm{O} 4$ and $\mathrm{N} 3$ in the pyrimidines). ${ }^{11,12}$

Though N7-methylguanine $(\mathrm{N} 7 \mathrm{mG})$ is the most vulnerable site, yet O6-methylguanine $(\mathrm{O} 6 \mathrm{mG})$ has been found to be very toxic, mutagenic and carcinogenic base across various methylated DNA bases. ${ }^{13-15}$ O6mG mispairs with thymine during the DNA replication which causes GC-AT transversion mutation and cancer. ${ }^{16-20}$ O6-alkylguanine-DNA alkyltransferase (AGT) or O6-methylguanine-DNA methyltransferase (MGMT) enzyme, repairs $\mathrm{O} 6 \mathrm{mG}$ via transferring methyl group from O6 position of guanine to S15 of the cysteine residue (Cys145 in human MGMT) in an irreversible stoichiometric reaction..$^{21,22}$
Many studies were conducted on the repair of $\mathrm{O} 6 \mathrm{mG}$ by the MGMT protein, in which the proton simultaneously transfers with methyl in the absence of solvent molecules. ${ }^{23,24}$ There are also some studies in which one part of MGMT, i.e., Cys145, Arg or Tyr to accompany in the repair processes of O6mG to $\mathrm{G}^{23,25,26}$

In the present study, a novel path for the repair of $\mathrm{O} 6 \mathrm{mG}$ by Cys 145 has been suggested and that its energy barrier is lower than those of the mechanisms that was previously suggested by P. K. Shukla et al. ${ }^{23}$ This study emphasizes the role of the solvent molecules and the proton transfer from Cys145 to O6mG on the repair process of O6mG by Cys145. The solvent effects were investigated by locating some water molecules around the complex and between the components as bridges and also using a continuum medium as solvent. The proton is transferred before methyl and also simultaneously with it. The process has also been studied in the acidic environment using protonation of the N7 and N3 sites. Results of this work give helpful insights to the repair mechanisms of the damaged DNA bases on the basis of proton transfer between the DNA bases and nucleic acids.

\section{Computational}

The effects of hydrogen bonds between Tyr114, Lys165, and Ser159 and the N3, N1 and O6 atoms on the repair process of $\mathrm{O} 6 \mathrm{mG}$ have previously been

*For correspondence 
investigated by Jena et. $a l .{ }^{27}$ In the present study, the effects of hydrogen bonds, whether mediated by $\mathrm{H}_{2} \mathrm{O}$ molecules or not, between Cys145 and O6mG, solvent molecules surrounding the components, and the protonation of $\mathrm{N} 3$ and $\mathrm{N} 7$ sites of $\mathrm{O} 6 \mathrm{mG}$ on the repair process have been considered.

Herein, the repair process of $06 \mathrm{mG}$ has been considered using six models: (1) only the O6mG and Cys145 components are considered along the process, (2) two water molecules bridged between main components and the proton transfer is approximately synchronized with the methyl transfer (3), two water molecules bridged between main components and the proton transfer precedes the methyl transfer (4) nine water molecules located around the components in order to consider the effect of water solvent on the repair process, (5) protonated $\mathrm{O} 6 \mathrm{mG}$ (at N7 site) is repaired by Cys145, and (6) protonated O6mG (at N3 \& N7 sites) is repaired by Cys 145 . All geometries were optimized by the Gaussian $09^{27}$ program package using the hybrid density functional B3LYP in conjunction with the $6-311++\mathrm{G}^{* *}$ basis set. $^{28,29}$

The solvent aqueous media effects on the reaction energy were also treated using the polarizable continuum model (PCM). ${ }^{30}$ Single-point calculations were carried out using the B3LYP and MP2 methods in conjunction with the AUG-cc-pVDZ and $6-311++\mathrm{G}^{* *}$ basis set respectively, in both gas phase and aqueous media. ${ }^{31,32}$ All stationary points verified by vibrational frequency analysis was carried out at the B3LYP/6-311++G** level of theory. All vibrational frequencies are positive for reactant and product complexes, and only one imaginary frequency is observed for each transition state. The net atomic charges were calculated using the ChelpG scheme on the structures optimized at the above mentioned level. ${ }^{33}$

To determine the special characters of the structures in stationary points along the repair process, population analysis has been performed by the natural bond orbital (NBO) $)^{34}$ method on the wave functions obtained at the HF/6-311++ $\mathrm{G}^{* *}$ level of theory by NBO3.135 program.

\section{Results and Discussion}

The cis and trans-O6mG conformers are different in the orientation of methyl group. In addition, cis-O6mG is more stable than trans-O6mG..$^{23,25}$ There are two conformers for Cys $145 ;{ }^{23,36}$ herein, stable conformer were selected in the calculations.

\subsection{Effect of proton transfer on the repair process of O6mG in the presence of cysteine: Model 1}

The cysteine thiolate anion facilitates the repair of O6mG. ${ }^{23}$ The negative charge on Cys145 helps separate the methyl group and facilitates the repair process. It has been previously proposed ${ }^{23}$ that the proton is transferred from S15 site of Cys145 to the histidine through a bridged water molecule and so the negative charge is located on Cys 145. The next steps of repair are the transfer of one proton from Cys145 or environment to $\mathrm{O} 6 \mathrm{mG}$ and methyl transfer from O6mG to Cys145. Is the proton transfer from Cys145 to $\mathrm{O} 6 \mathrm{mG}$ prior to the methyl transfer or simultaneous with it? In order to answer this question, two pathways were considered in the repair mechanism: (1) the proton is transferred before the methyl migration, and (2) the proton and the methyl transfer take place at the same time. Herein, the binary complex of O6mG and Cys145 is stabilized by two strong hydrogen bonds, $\mathrm{O} 26 \mathrm{H} 27 \cdots \mathrm{N} 1(1.84 \AA)$ and $\mathrm{N} 2 \mathrm{H} 2 \cdots \mathrm{O} 25(1.90 \AA)$. The second path has previously been considered by Shukla et al. ${ }^{23}$ The most important stationary points including the reactant complex (RC), two transition states (TS1 and TS2), one intermediate (INT) and the product complex (PC) have been considered in the first pathway. The gas phase structures optimized at the B3LYP/6-311++G** level of theory are shown in figure 1.

The transfer of $\mathrm{H} 27$ from Cys145 to O6mG leads to INT via $\mathbf{T S}_{\mathbf{1}}(\mathbf{1})$. Subsequently, $\mathbf{P C}(\mathbf{1})$ is made from INT via $\mathbf{T S}_{\mathbf{2}}(\mathbf{1})$, in which the methyl group is transferred from $\mathrm{O} 6 \mathrm{mG}$ to Cys145. The proton transfer from S15 site of Cys145 to histidine has previously been considered $^{23}$ through a bridged water molecule before methyl transfer. In fact, the negative charge on S15 site of Cys145 facilitates the methyl transfer and the repair process.

As can be seen from geometrical parameters, the proton transfer weakens the O6-C10 bond and pushes the $\mathrm{C} 10$ atom to a point on the direct path between $\mathrm{O} 6$ and S15, and therefore decreases the energy barrier in the latter step. The barrier $\Delta \mathrm{E}^{1}$ corrected for zero-point energy (ZPE) and the Gibbs free energy $\Delta \mathrm{G}^{1}$ at different levels of theory obtained in the gas phase and aqueous media are presented in table 1 . The $\Delta \mathrm{E}_{\mathrm{p}, \mathrm{f}}^{1}$ and $\Delta \mathrm{G}_{\mathrm{p}, \mathrm{f}}^{1}$ are equal to 4.74 and $2.87 \mathrm{kcal} \mathrm{mol}^{-1}$ for the first step and $\Delta \mathrm{E}_{\mathrm{m}, \mathrm{f}}^{1}$ and $\Delta \mathrm{G}_{\mathrm{m}, \mathrm{f}}^{1}$ are equal to 28.18 and $29.92 \mathrm{kcal} \mathrm{mol}^{-1}$ for the second step in the gas phase at the B3LYP/6-311++ $\mathrm{G}^{* *}$ level of theory (table 1). The repair of $\mathrm{O} 6 \mathrm{mG}$ to guanine was considered in the presence of Cys 145 via $\mathrm{S}_{\mathrm{N}} 2$ mechanism, in which $\Delta \mathrm{E}_{\mathrm{m}, \mathrm{f}}^{1}$ obtained $34.2 \mathrm{kcal} \mathrm{mol}^{-1}$ at the B3LYP/6$311++\mathrm{G}^{* *}$ level of theory in the gas phase. ${ }^{23}$ Thus, the 


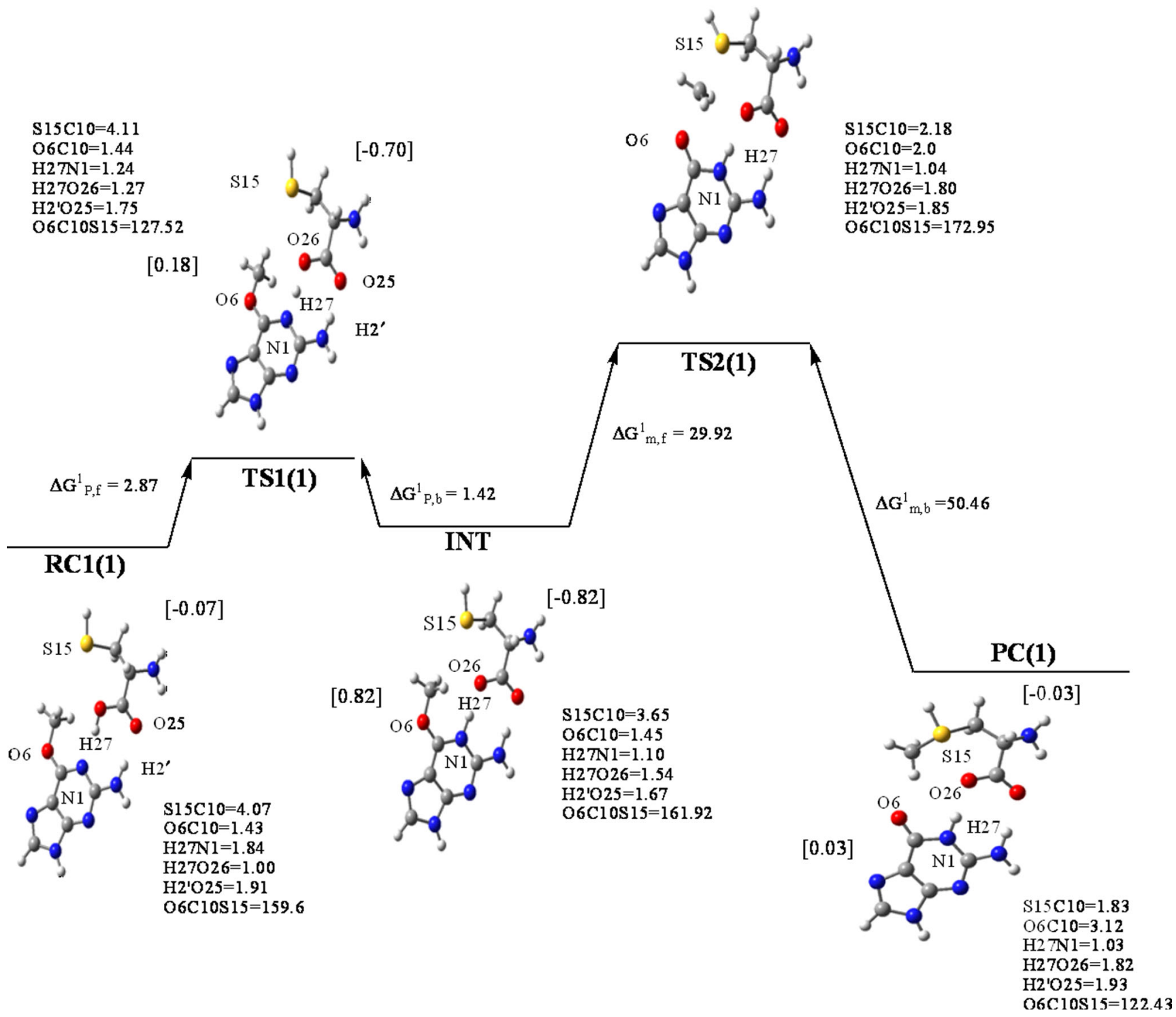

Figure 1. Repair of O6mG to guanine by Cys145. The structures of reactant RC(1), transition states TS1(1) and TS2(1), and product PC(1) complexes optimized at the B3LYP/6-311++ $\mathrm{G}^{* *}$ level of theory. The Gibbs free energies (in kcal mol ${ }^{-1}$ ) and the net ChelpG charges are shown in the figure.

$\Delta \mathrm{E}_{\mathrm{m}, \mathrm{f}}^{1}$ value for the repair of $\mathrm{O} 6 \mathrm{mG}$ in the presence of Cys 145 reduces by $6.02 \mathrm{kcal} \mathrm{mol}^{-1}$ along the two-step mechanism.

As can be seen in table $1, \Delta$ values of proton transfer change by $1.28-4.74 \mathrm{kcal} \mathrm{mol}^{-1}$ when basis set changes from $6-311++\mathrm{G}^{* *}$ to AUG-cc-pVDZ and by $3.56-$ $4.74 \mathrm{kcal} \mathrm{mol}^{-1}$ when method changes from B3LYP to MP2. These ranges are $28.18-28.87 \mathrm{kcal} \mathrm{mol}^{-1}$ and $28.18-28.22 \mathrm{kcal} \mathrm{mol}^{-1}$ for methyl transfer, respectively. Thus, negligible changes are observed by the change in the level of computation in both $\Delta$ values.

The $\Delta \mathrm{E}_{\mathrm{m}, \mathrm{f}}^{1}$ and $\Delta \mathrm{G}_{\mathrm{m}, \mathrm{f}}^{1}$ values calculated at different levels of theory are given in table 1. In the gas phase, the energy barrier increases by $\sim 2.41 \%$ by changing the basis set from $6-311++\mathrm{G}^{* *}$ to
AUG-cc-pVDZ using the B3LYP method and increases by $\sim 0.14 \%$ by changing the method from B3LYP to MP2 using the $6-311++\mathrm{G}^{* *}$ basis set. In going from the gas phase to aqueous media, the value of $\Delta \mathrm{E}_{\mathrm{m}, \mathrm{f}}^{1}$ is reduced by $4.37,4.84$ and $1.59 \mathrm{kcal} \mathrm{mol}^{-1}$ at the B3LYP/6-311++G**, B3LYP/AUG-cc-pVDZ and MP2/6-311++ $\mathrm{G}^{* *}$ levels of theory, respectively, and almost the same is also found to be true for the corresponding values $\Delta \mathrm{G}_{\mathrm{m}, \mathrm{f}}^{1}$ (table 1$)$.

The effects of proton transfer from Cys145 to histidine $\left(\Delta \mathrm{E}=9.2 \mathrm{kcal} \mathrm{mol}^{-1}\right)$ and the tyrosine... $\mathrm{N} 3$ hydrogen bond on the repair process of $\mathrm{O} 6 \mathrm{mG}$ $\left(\Delta \mathrm{E}_{\text {methyl }}=18.2\right.$ and $21.2 \mathrm{kcal} \mathrm{mol}^{-1}$, the latter were obtained in the presence of solvent) were considered by Georgieva et al. ${ }^{37}$ In the present work, the effects 
Table 1. The barrier energies $\left(\Delta \mathrm{E}\right.$ and $\Delta \mathrm{G}$ in kcal mol${ }^{-1}$ ) involved in the repair of $06 \mathrm{mG}$ with Cys145 at different levels of theory for model $\mathbf{1}$.

\begin{tabular}{lccc}
\hline & $\begin{array}{c}\text { B3LYP } \\
6-311++\mathrm{G}^{* *}\end{array}$ & $\begin{array}{c}\text { B3LYP } \\
\text { AUG-cc-pVDZ }\end{array}$ & $\begin{array}{c}\text { MP2 } \\
6-311++\mathrm{G}^{* *}\end{array}$ \\
\hline$\Delta \mathrm{E}_{\mathrm{p}, \mathrm{f}}^{1}$ & $4.74(4.18)$ & $1.28(1.159)$ & $3.56(3.26)$ \\
$\Delta \mathrm{E}_{\mathrm{p}, \mathrm{b}}^{1}$ & $1.82(2.17)$ & $1.97(1.13)$ & $2.22(2.19)$ \\
$\Delta \mathrm{G}_{\mathrm{p}, \mathrm{f}}^{1}$ & $2.87(1.63)$ & $1.97(1.13)$ & $4.58(3.43)$ \\
$\Delta \mathrm{G}_{\mathrm{p}, \mathrm{b}}^{1}$ & $1.42(0.75)$ & $2.04(0.08)$ & $2.29(1.14)$ \\
$\Delta \mathrm{E}_{\mathrm{m}, \mathrm{f}}^{1}$ & $28.18(23.81)$ & $28.87(24.01)$ & $28.22(26.63)$ \\
$\Delta \mathrm{E}_{\mathrm{m}, \mathrm{b}}^{1}$ & $49.62(25.48)$ & $51.17(22.06)$ & $57.45(29.71)$ \\
$\Delta \mathrm{G}_{\mathrm{m}, \mathrm{f}}^{1}$ & $29.92(24.40)$ & $30.37(25.30)$ & $29.72(27.46)$ \\
$\Delta \mathrm{G}_{\mathrm{m}, \mathrm{b}}^{1}$ & $50.46(22.58)$ & $49.56(21.96)$ & $56.58(29.61)$ \\
\hline
\end{tabular}

Energies obtained in aqueous media are given in the parentheses. (p: proton transfer, m: methyl transfer, f: forward and b: backward)

of intermolecular hydrogen bond between Cys145 and $\mathrm{N} 1$, and thus, the proton transfer from Cys 145 to O6mG on the repair process has been considered both in the absence (present section) and in the presence of solvent $\mathrm{H}_{2} \mathrm{O}$ molecules (next section). The energy barrier for TS1, which corresponds to the proton transfer, is equal to $4.74 \mathrm{kcal} \mathrm{mol}^{-1}$ in model 1 .

With respect to the ChelpG charges calculated on O6mG (0.074 e) and Cys145 (-0.074 e), the components are expected to be neutral in the $\mathbf{R C}(\mathbf{1})$ point. In $\mathbf{T S}_{\mathbf{1}}(\mathbf{1})$, in which corresponds to the proton transfer, the charges calculated on O6mG and Cys145 are equal to 0.18 and -0.70 e, respectively. The charges calculated on the mentioned components are equal to 0.82 and -0.82 e when proton transfer is completed in INT. Thus, after proton transfer, O6mG has a higher tendency to transfer the methyl group and reduces the positive charge density. The progress in the methyl transfer changes the charges on the components to 0.11 and -0.55 e, respectively, in $\mathbf{T} \mathbf{S}_{\mathbf{2}}$. Finally, the methyl group attaches to Cys145 and completes the repair process in $\mathbf{P C}(\mathbf{1})$.

In order to explore other features of stationary points on the repair process, the NBO analysis has also been carried out on the wave functions obtained at the HF/6$311++\mathrm{G}^{* *}$ level of theory. The weakening of the O26$\mathrm{H} 27$ bond is accompanied by the increase in the occupation number of the $\sigma^{*}{ }_{\mathrm{O} 26 \mathrm{H} 27}$ orbital and the decrease in the occupation number of $\sigma_{\mathrm{O} 26 \mathrm{H} 27}$ orbital in $\mathbf{R C}(\mathbf{1})$, and is continued until the $\mathrm{O} 26-\mathrm{H} 27$ bond cleavage is completed in the INT structure.

The sum of the donor-acceptor energies $\left(\sum E^{2}\right)$ were calculated for the most important interactions. When the $\sigma^{*}{ }_{\mathrm{C} 26 \mathrm{C} 27}$ orbital acts as acceptor, the $\sum \mathrm{E}^{2}$ value for the cleavage of the $\mathrm{O} 26-\mathrm{H} 27$ bond in $\mathbf{T S}_{\mathbf{1}}(\mathbf{1})$ is $32.41 \mathrm{kcal} \mathrm{mol}^{-1}$. On the other hand, when the $\sigma^{*}{ }_{\mathrm{O} 6 \mathrm{C} 10}$ is an acceptor, the $\sum E^{2}$ value for the cleavage of the O6-C10 bond in $\mathbf{T S}_{\mathbf{2}}(\mathbf{1})$ is $36.06 \mathrm{kcal} \mathrm{mol}^{-1}$.

Similarly, the weakening of O6-C10 bond is accompanied by the increase in the occupation number of the $\sigma^{*}{ }_{\mathrm{O} 6 \mathrm{C} 10}$ orbital and the decrease in the occupation number of the $\sigma_{\mathrm{O} 6 \mathrm{C} 10}$ orbital in $\mathbf{T S}_{\mathbf{2}}(\mathbf{1})$, and is continued until the O6-C10 bond cleavage is completed in the PC structure and methyl group locates on S15 site of Cys145. The most important interactions which affect the weakening of the $\mathrm{O} 26-\mathrm{H} 27$ and $\mathrm{O} 6-\mathrm{C} 10$ bonds are $\mathrm{lp}_{\mathrm{N} 1} \rightarrow \sigma^{*}{ }_{\mathrm{O} 26 \mathrm{H} 27}$ and $\mathrm{lp}_{\mathrm{S} 15} \rightarrow \sigma^{*}{ }_{\mathrm{O} 6 \mathrm{C} 10}$, respectively.

With respect to the energy gap between HOMO and LUMO, which are equal to 6.76 and $5.35 \mathrm{eV}$ for $\mathbf{R C}$ and INT in the one step and two steps pathways, INT is more reactive than $\mathbf{R C}$ with a lower energy barrier in the gas phase.

\subsection{The repair process in the presence of water molecules: Models 2 and 3}

The effects of bridged and surrounding water molecules on the proton transfer from Cys145 (O26 site) to O6mG (N1 site) and on other aspects of repair process have been investigated in this section. In model (2), only two water molecules bridged between $\mathrm{O} 6 \mathrm{mG}$ and Cys 145 via four hydrogen bonds $\mathrm{O} 26 \mathrm{H} 27 \cdots \mathrm{O} 28$, $\mathrm{O} 28 \mathrm{H} 29 \cdots \mathrm{N} 1, \mathrm{O} 31 \mathrm{H} 30 \cdots \mathrm{O} 25$ and $\mathrm{N} 2 \mathrm{H} 2 \cdots \mathrm{O} 31$ (figure 2). The H-bond lengths lie in the range of 1.58$2.07 \AA$. Herein, the proton transfer from Cys145 to $\mathrm{O} 6 \mathrm{mG}$ can be mediated by a water molecule. H27 is transferred from Cys145 to a water molecule and H29 is simultaneously transferred from a water molecule to the N1 site of O6mG. In the next step, the methyl group is transferred to Cys145 and the repair process is completed. Without proton transfer, the repair mechanism that involves a single transition state can be considered $S_{N} 2$. The energy barrier of methyl transfer is $37.51 \mathrm{kcal} \mathrm{mol}^{-1}$ which is $9.33 \mathrm{kcal} \mathrm{mol}^{-1}$ higher than that in the model (1). Thus, the bridged water molecules can increase the energy barrier of the repair process.

The $\Delta \mathrm{E}_{\mathrm{m}, \mathrm{f}}^{2}$ and $\Delta \mathrm{G}_{\mathrm{m}, \mathrm{f}}^{2}$ values obtained at different levels are given in table 2. $\Delta \mathrm{E}_{\mathrm{m}, \mathrm{f}}^{2}$ is $37.51 \mathrm{kcal} \mathrm{mol}^{-1}$ in the gas phase at the B3LYP/6-311++G** level of theory. In the gas phase, the energy barrier increases by $\sim 1.90 \%$ in changing the basis set from $6-311++\mathrm{G}^{* *}$ to AUG-cc-pVDZ using the B3LYP method, while this value increases by $\sim 0.58 \%$ by changing the method from B3LYP to MP2 using the 6-311++ $\mathrm{G}^{* *}$ basis set. 


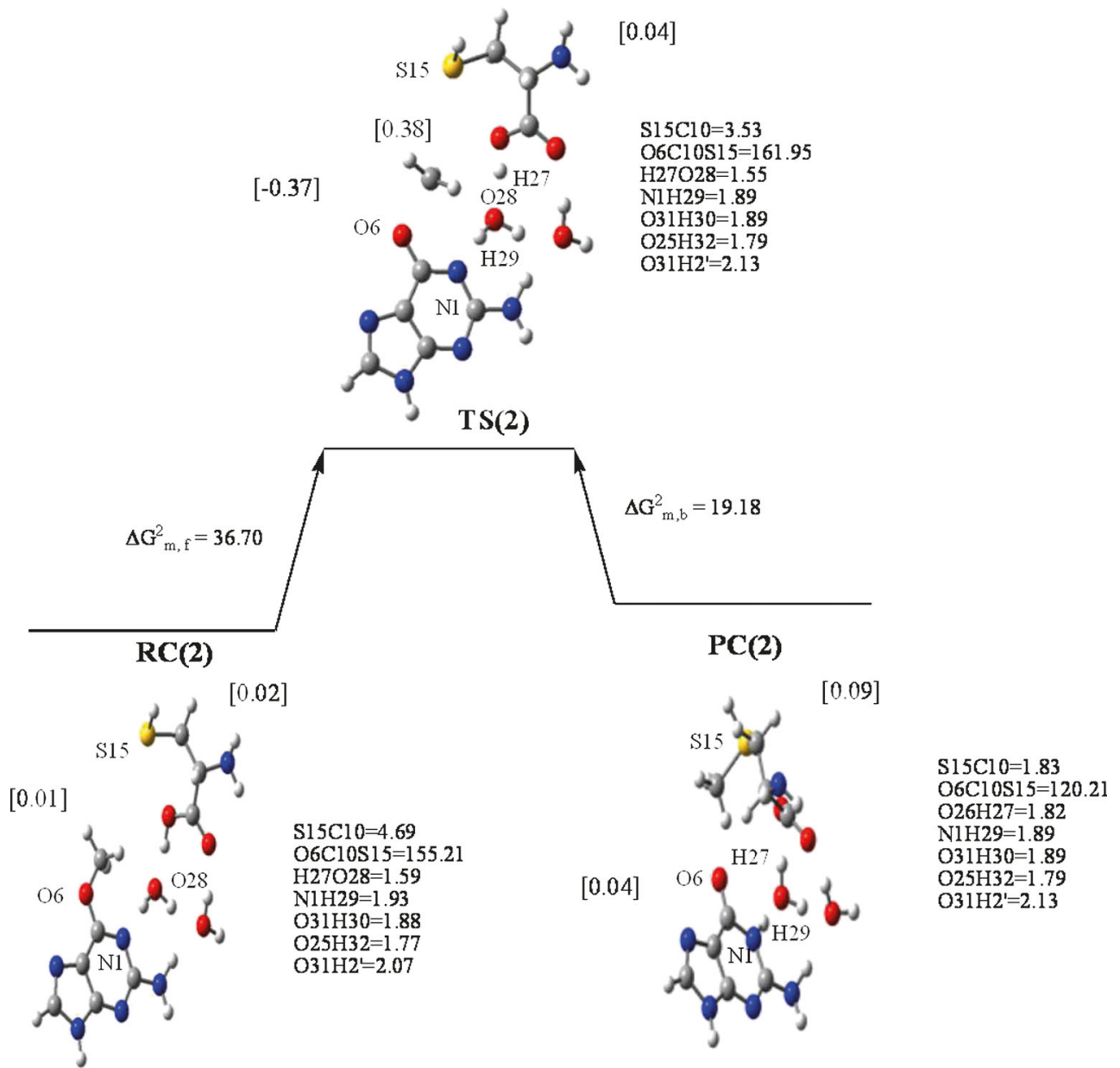

Figure 2. Repair of $\mathrm{O} 6 \mathrm{mG}$ to guanine by Cys145 in the presence of two bridged water molecules when proton is transferred through water molecules simultaneously with methyl group. The structures of reactant $\mathbf{R C}(2)$, transition state $\mathbf{T S}(2)$ and product $\mathbf{P C}(2)$ complexes optimized at the B3LYP/6-311++G** level of theory. The Gibbs free energies (in $\mathrm{kcal} \mathrm{mol}^{-1}$ ) and the net ChelpG charges are shown in the figure.

In going from the gas phase to aqueous media, the value of $\Delta \mathrm{E}_{\mathrm{m}, \mathrm{f}}^{2}$ is reduced by $2.71,4.65$ and $0.21 \mathrm{kcal} \mathrm{mol}^{-1}$ at the B3LYP/6-31++G**, B3LYP/AUG-cc-pVDZ and MP2/6-311++G** levels of theory, respectively. Similar results are also obtained for the $\Delta \mathrm{G}_{\mathrm{m}, \mathrm{f}}^{2}$ values (table 2).

The CHelpG charges calculated on O6mG, Cys 145 and the water molecules of $\mathbf{R C}(2)$ are approximately equal to zero and the system is neutral. The charge on O6mG, Cys145, the water molecules, and the methyl group of $\mathbf{T S}(2)$ is equal to $-0.36,0.04,-0.06$ and 0.38 $\mathrm{e}$, respectively. Thus, the electron density is more localized on O6mG in TS(2). After transition state, the proton is transferred through a bridged water molecule and it reduces the negative charge of guanine.

With respect to the NBO analysis, the most important interaction in which the $\sigma^{*}{ }_{\mathrm{O} 26 \mathrm{H} 27}$ orbital acts as acceptor
Table 2. The barrier energies ( $\Delta \mathrm{E}$ and $\Delta \mathrm{G}$ in $\mathrm{kcal} \mathrm{mol}^{-1}$ ) involved in the reaction of $\mathrm{O} 6 \mathrm{mG}$ with Cys145 at different levels of theory for models $\mathbf{2}$ and $\mathbf{3}$.

\begin{tabular}{lccc}
\hline & $\begin{array}{c}\text { B3LYP } \\
6-311++\mathrm{G}^{* *}\end{array}$ & $\begin{array}{c}\text { B3LYP } \\
\text { AUG-cc-pVDZ }\end{array}$ & $\begin{array}{c}\text { MP2 } \\
6-311++\mathrm{G}^{* *}\end{array}$ \\
\hline$\Delta \mathrm{E}_{\mathrm{m}, \mathrm{f}}^{2}$ & $37.51(34.80)$ & $38.23(33.58)$ & $37.29(37.45)$ \\
$\Delta \mathrm{E}_{\mathrm{m}, \mathrm{b}}^{2}$ & $23.72(4.12)$ & $35.29(15.03)$ & $27.19(16.12)$ \\
$\Delta \mathrm{G}_{\mathrm{m}, \mathrm{f}}^{2}$ & $36.70(37.88)$ & $36.37(37.65)$ & $38.37(41.50)$ \\
$\Delta \mathrm{G}_{\mathrm{m}, \mathrm{b}}^{2}$ & $19.17(18.27)$ & $17.01(17.48)$ & $25.91(20.10)$ \\
$\Delta \mathrm{E}_{\mathrm{m}, \mathrm{f}}^{3}$ & $25.71(24.70)$ & $24.74(21.77)$ & $22.16(20.10)$ \\
$\Delta \mathrm{E}_{\mathrm{m}, \mathrm{b}}^{3}$ & $19.89(20.31)$ & $18.18(16.27)$ & $23.40(21.64)$ \\
$\Delta \mathrm{G}_{\mathrm{m}, \mathrm{f}}^{3}$ & $25.74(24.37)$ & $24.72(21.64)$ & $25.14(20.10)$ \\
$\Delta \mathrm{G}_{\mathrm{m}, \mathrm{f}}^{3}$ & $21.86(20.07)$ & $20.42(21.14)$ & $25.64(29.23)$ \\
\hline
\end{tabular}

Energies obtained in aqueous media are given in the parentheses. (m: methyl transfer, f: forward and b: backward) 
is $\mathrm{lp}_{\mathrm{O} 28} \rightarrow \sigma^{*}{ }_{\mathrm{O} 26 \mathrm{H} 27}$. This interaction, which increases the occupation number of the $\sigma^{*}{ }_{\mathrm{O} 26 \mathrm{H} 27}$ orbital, in TS(2) is stronger than $\mathbf{R C}(\mathbf{2})$. The energy of mentioned donor-acceptor interaction which helps the cleavage of $\mathrm{O} 26-\mathrm{H} 27$ bond and shifts the $\mathrm{H} 27$ atom towards the O28 site is equal to $47.33 \mathrm{kcal} \mathrm{mol}^{-1}$ in $\mathbf{T S}(\mathbf{2})$. On the other hand, the N1 lone pair of O6mG helps the complex to weaken the $\mathrm{O} 28-\mathrm{H} 29$ bond. The $\mathrm{lp}_{\mathrm{N} 1} \rightarrow$ $\sigma^{*}{ }_{\mathrm{O} 28 \mathrm{H} 29}$ interaction energy increases from $\mathbf{R C}(2)$ to $\mathbf{T S}(2)$ and becomes $17.66 \mathrm{kcal} \mathrm{mol}^{-1}$ in TS(2). Finally, $\mathrm{H} 27$ attaches to the water molecule and $\mathrm{H} 29$ attaches to the N1 site of O6mG. This model has a lower $\sum E^{2}$ value (for interactions with $\sigma^{*}{ }_{\mathrm{O} 6 \mathrm{C} 10}$ ) and therefore a higher energy barrier $\left(\sim 10.37 \mathrm{kcal} \mathrm{mol}^{-1}\right)$ relative to the previous model.

The energy barrier is reduced in the presence of water molecules when the proton transfer occurs before methyl migration. Herein, the energy barrier of methyl transfer is equal to $25.71 \mathrm{kcal} \mathrm{mol}^{-1}$ (figure 3) and increases to $37.51 \mathrm{kcal} \mathrm{mol}^{-1}$ when the proton transfer is not considered in a separate step.

The $\Delta \mathrm{E}_{\mathrm{m}, \mathrm{f}}^{3}$ value calculated at the B3LYP/6$311++\mathrm{G}^{* *}$ level and the results of single-point energy calculations at the B3LYP/AUG-cc-pVDZ and MP2/6$311++\mathrm{G}^{* *}$ levels are also given in table 2 . The energy barrier increases by $\sim 3.85 \%$ in changing the basis set from 6-311++G** to AUG-cc-pVDZ using the B3LYP method, while that value increases by $\sim 14.83 \%$ in changing the method from B3LYP to MP2 using the $6-311++\mathrm{G}^{* *}$ basis set in the gas phase (table 2). In going from the gas phase to aqueous media, the value of $\Delta \mathrm{E}_{\mathrm{m}, \mathrm{f}}^{3}$ reduces by $1.01,2.97$ and $2.06 \mathrm{kcal} \mathrm{mol}^{-1}$ at the B3LYP/6-31++G**, B3LYP/AUG-cc-pVDZ and MP2/6-311++G** levels of theory, respectively. Similar results are also obtained for the $\Delta \mathrm{G}_{\mathrm{m}, \mathrm{f}}^{3}$ values (table 2).

The charges calculated on $\mathrm{O} 6 \mathrm{mG}, \mathrm{Cys} 145$ and two water molecules are equal to $0.87,-0.76$ and -0.11 ,
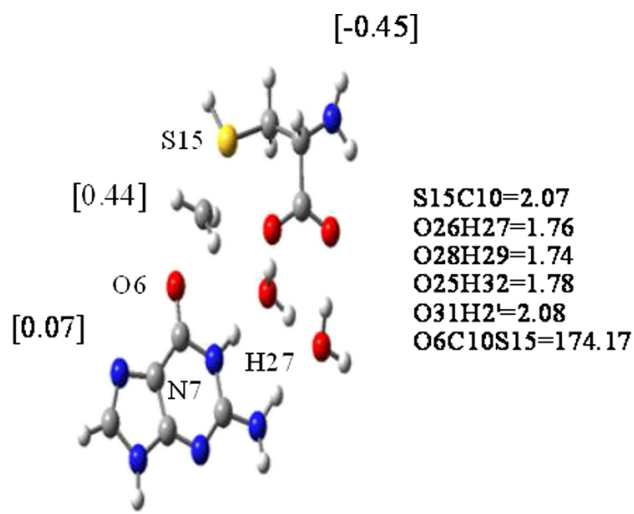

TS(3)

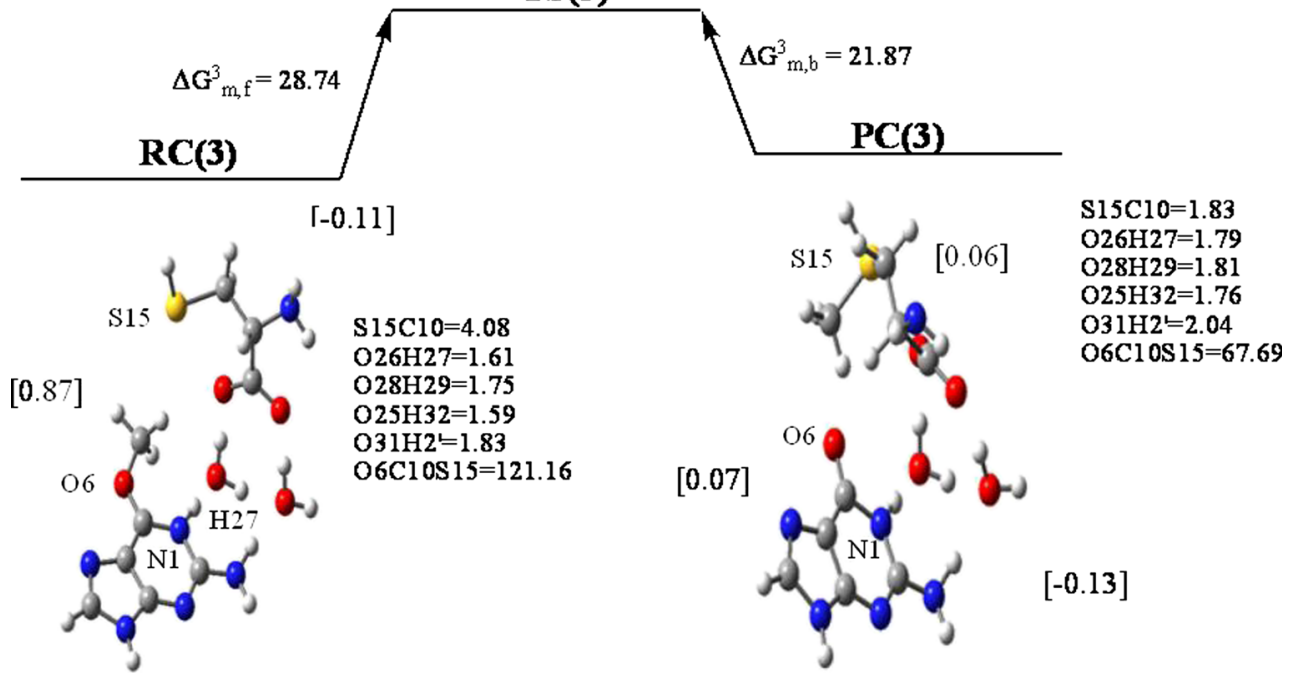

Figure 3. Repair of O6mG to guanine by Cys 145 in the presence of two water molecules when proton is transferred through water molecules before methyl transfer. The structures of reactant $\mathbf{R C}(3)$, transition state $\mathbf{T S}(3)$, and product $\mathbf{P C}(\mathbf{3})$ complexes optimized at the B3LYP/6-311++G** level of theory. The Gibbs free energies (in $\mathrm{kcal} \mathrm{mol}^{-1}$ ) and the net ChelpG charges are shown in the figure. 
respectively, in $\mathbf{R C}(\mathbf{3})$ in the model (3). The positive charge on $\mathrm{O} 6 \mathrm{mG}$ can speed up methyl migration to Cys145. In TS(3), the calculated charges on the guanine, Cys145, the methyl group and the two water molecules are $0.07,-0.44,0.44$ and $-0.06 \mathrm{e}$, respectively. All moieties are approximately neutral in PC(3).

The most important interaction with $\sigma^{*}{ }_{\mathrm{O} 6 \mathrm{C} 10}$ is $\operatorname{lp}_{\mathrm{S} 15} \rightarrow \sigma^{*}{ }_{\mathrm{O} 6 \mathrm{C} 10}$ which increases the occupancy of the $\sigma^{*}{ }_{\mathrm{O} 6 \mathrm{C} 10}$ orbital. The $\mathrm{E}^{2}$ value of $\mathrm{lp}_{\mathrm{S} 15} \rightarrow \sigma^{*}{ }_{\mathrm{O} 6 \mathrm{C} 10}$ interaction increases from $\mathbf{R C}(3)\left(0.34 \mathrm{kcal} \mathrm{mol}^{-1}\right)$ to TS(3) $\left(34.22 \mathrm{kcal} \mathrm{mol}^{-1}\right)$. The $\sum \mathrm{E}^{2}$ value for interactions with $\sigma^{*}{ }_{\mathrm{O} 6 \mathrm{C} 10}$ is $39.29 \mathrm{kcal} \mathrm{mol}^{-1}$ in $\mathbf{T S}(\mathbf{3})$. In comparison with the previous models, higher $\sum E^{2}$ value reduces the energy barrier in this model. The energy gap between the HOMO and LUMO in $\mathbf{R C}(2)$ and $\mathbf{R C}(3)$ is equal to 6.74 and $4.88 \mathrm{eV}$, in the gas phase. This result is in agreement with the greater reactivity of $\mathbf{R C}(3)$.

In addition to bridged water molecules, seven water molecules were located around the components in model (4) (figure 4). Herein, it is assumed that the proton transfer occurs before the methyl transfer. The $\Delta \mathrm{E}_{\mathrm{m}, \mathrm{f}}^{4}$ value calculated at various levels of theory are given in table 3. The values of $\Delta \mathrm{E}_{\mathrm{m}, \mathrm{f}}^{4}$ and $\Delta \mathrm{G}_{\mathrm{m}, \mathrm{f}}^{4}$ are equal to 26.26 and $24.59 \mathrm{kcal} \mathrm{mol}^{-1}$, respectively. The water molecules located between the components reduce the energy barrier, but the water molecules arranged around the components do not affect the barrier.

The $\Delta \mathrm{E}_{\mathrm{m}, \mathrm{f}}^{4}$ and $\Delta \mathrm{G}_{\mathrm{m}, \mathrm{f}}^{4}$ values obtained at different levels are given in table 3 . In the gas phase, the energy barrier increases by $\sim 9.04 \%$ in changing the basis set

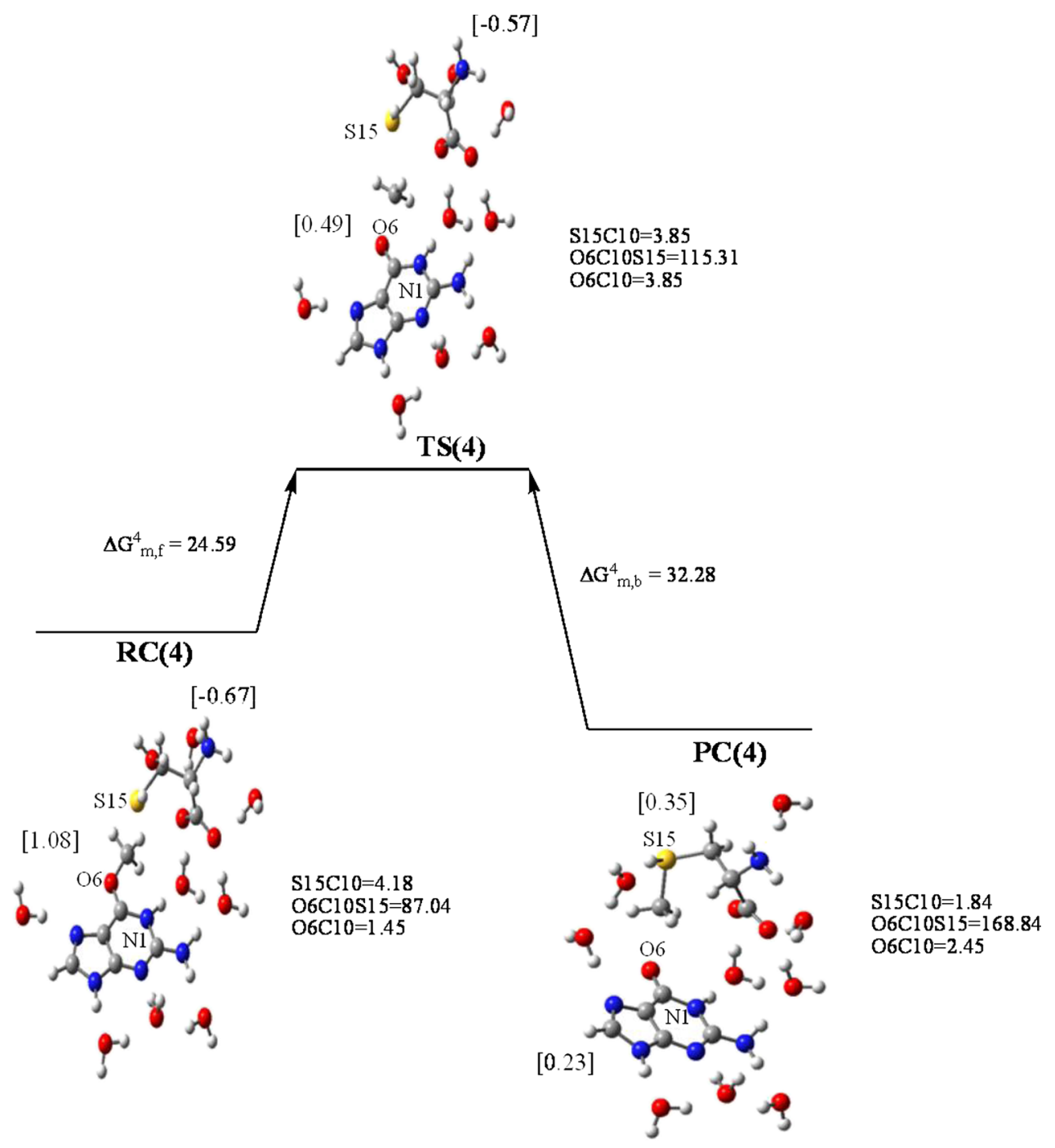

Figure 4. Repair of O6mG to guanine by Cys145 in the presence of solvent water molecules. The structures of reactant RC(4), transition states TS(4) and product PC(4) complexes optimized at the B3LYP/6-311++G** level of theory. The Gibbs free energies (in $\mathrm{kcal} \mathrm{mol}^{-1}$ ) and the net ChelpG charges are shown in the figure. 
Table 3. The barrier energies ( $\Delta \mathrm{E}$ and $\Delta \mathrm{G}$ in $\mathrm{kcal} \mathrm{mol}^{-1}$ ) involved in the repair of O6mG with Cys145 at different levels of theory for model 4.

\begin{tabular}{lccc}
\hline & $\begin{array}{c}\text { B3LYP } \\
6-311++\mathrm{G}^{* *}\end{array}$ & $\begin{array}{c}\text { B3LYP } \\
\text { AUG-cc-pVDZ }\end{array}$ & $\begin{array}{c}\text { MP2 } \\
6-311++\mathrm{G}^{* *}\end{array}$ \\
\hline$\Delta \mathrm{E}_{\mathrm{m}, \mathrm{f}}^{4}$ & 26.26 & 23.99 & 27.32 \\
$\Delta \mathrm{E}_{\mathrm{m}, \mathrm{b}}^{4}$ & 42.00 & 35.14 & 46.25 \\
$\Delta \mathrm{G}_{\mathrm{m}, \mathrm{f}}^{4}$ & 24.59 & 24.46 & 27.79 \\
$\Delta \mathrm{G}_{\mathrm{m}, \mathrm{b}}^{4}$ & 32.28 & 29.54 & 40.65 \\
\hline
\end{tabular}

(m: methyl transfer, f: forward and b: backward)

from 6-311++G** to AUG-cc-pVDZ using the B3LYP method while that increases by $\sim 3.9 \%$ in changing the method from B3LYP to MP2 using the 6-311++G** basis set (table 3 ). The $\Delta \mathrm{E}_{\mathrm{m}, \mathrm{f}}^{4}$ value increases by $\sim 2.1 \%$ and the $\Delta \mathrm{G}_{\mathrm{m}, \mathrm{f}}^{4}$ value decreases by $15.5 \%$ in changing the model from (3) to (4).

\subsection{The effect of acidic environment: Models 5 and 6}

The energy barrier decreases to 30.57 and $17.85 \mathrm{kcal}$ $\mathrm{mol}^{-1}$ by protonation of the $\mathrm{N} 7$ site of $\mathrm{O} 6 \mathrm{mG}$ in the model(5) (figure 5) and protonation of both the N7 and $\mathrm{N} 3$ sites of $\mathrm{O} 6 \mathrm{mG}$ in the model(6) (figure 6), respectively. RC(5) and $\mathbf{R C}(\mathbf{6})$ have the same O6-C10 bond lengths $(\sim 1.46 \AA)$. The most important geometrical parameters of TS (5), i.e., O6-C10 and S15-C10 bond lengths, are equal to 1.96 and $2.56 \AA$. However, these bond lengths are equal to 2.05 and $5.87 \AA$ in TS (6).

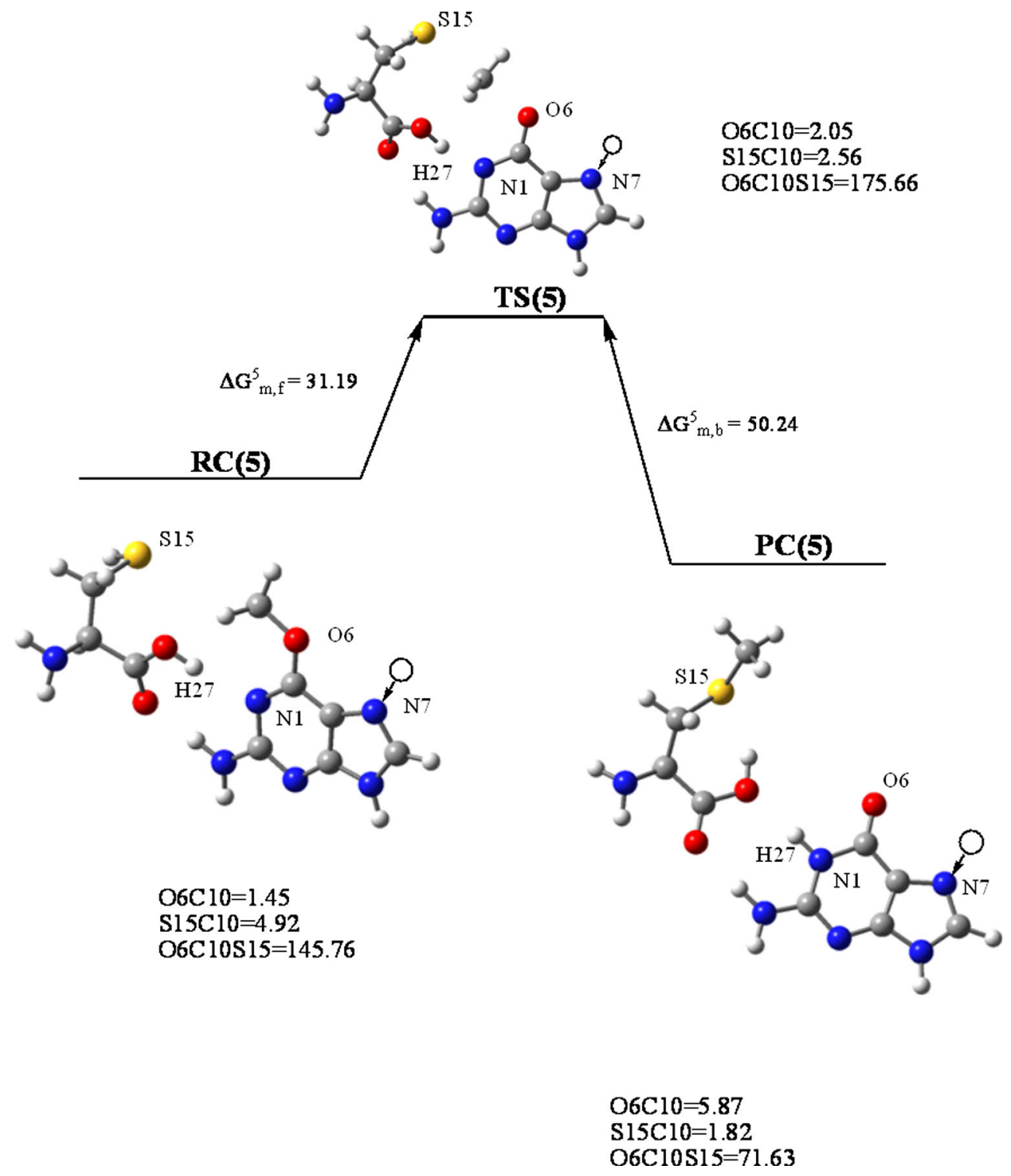

Figure 5. Repair of O6mG to guanine by Cys145; the protonated site is shown by a hollow circle. 
Therefore, the O6-C10 bond length increases by protonation of $\mathrm{O} 6 \mathrm{mG}$ and the repair process is facilitated in the acidic environment. The O6-C10 bond length indicates that the methyl transfer in model (6) is faster than model (5).

The $\Delta \mathrm{E}_{\mathrm{m}, \mathrm{f}}^{5}$ and $\Delta \mathrm{G}_{\mathrm{m}, \mathrm{f}}^{5}$ values obtained at different levels of theory in the gas phase and aqueous media are presented in table 4 . The $\Delta \mathrm{E}_{\mathrm{m}, \mathrm{f}}^{5}$ and $\Delta \mathrm{G}_{\mathrm{m}, \mathrm{f}}^{5}$ values are equal to 30.57 and $31.19 \mathrm{kcal} \mathrm{mol}^{-1}$ in the gas phase at the B3LYP/6-311++G** level of theory (table 4). As can be seen, protonation of the N7 site decreases the energy barrier. In going from the gas phase to aqueous media, the value of $\Delta \mathrm{E}_{\mathrm{m}, \mathrm{f}}^{5}$ is reduced by 1.16 , 0.98 and $1.31 \mathrm{kcal} \mathrm{mol}^{-1}$ at the B3LYP/6-31++G**, B3LYP/AUG-cc-pVDZ and MP2/6-311++G** levels of theory. Similar results are also obtained for the $\Delta \mathrm{G}_{\mathrm{m}, \mathrm{f}}^{5}$ values (table 4).

The ChelpG charges calculated on the $\mathrm{O} 6 \mathrm{mG}$ and Cys 145 components are equal to 1.03 and $-0.03 \mathrm{e}$, in $\mathbf{R C}(\mathbf{5})$. Herein, O6mG has a higher tendency to transfer the methyl group to Cys145 and reduces the positive charge density. The methyl transfer from O6mG to Cys 145 reduces the positive charge on guanine in TS(5). The charges calculated on the guanine, Cys145 and the methyl group are equal to 0.43, 0.37 and 0.19 e, respectively. Finally, the methyl group attaches to Cys145 and completes the repair process in PC(5).

The $\Delta \mathrm{E}_{\mathrm{m}, \mathrm{f}}^{6}$ and $\Delta \mathrm{G}_{\mathrm{m}, \mathrm{f}}^{6}$ values obtained at different levels of theory in the gas phase and aqueous media are presented in table 4 . The $\Delta \mathrm{E}_{\mathrm{m}, \mathrm{f}}^{6}$ and $\Delta \mathrm{G}_{\mathrm{m}, \mathrm{f}}^{6}$ values are equal to 17.85 and $16.57 \mathrm{kcal} \mathrm{mol}^{-1}$ in the gas phase at the B3LYP/6-311++G** level of theory (table 4). As can be seen, protonation of the $\mathrm{N} 3$ site of $06 \mathrm{mG}$ induces a more decrease in the energy barrier. In going from the gas phase to aqueous media, the value of $\Delta \mathrm{E}_{\mathrm{m}, \mathrm{f}}^{6}$ reduces by $1.38,0.49$ and $1.60 \mathrm{kcal} \mathrm{mol}^{-1}$ at the B3LYP/6-31++G**, B3LYP/AUG-cc-pVDZ and

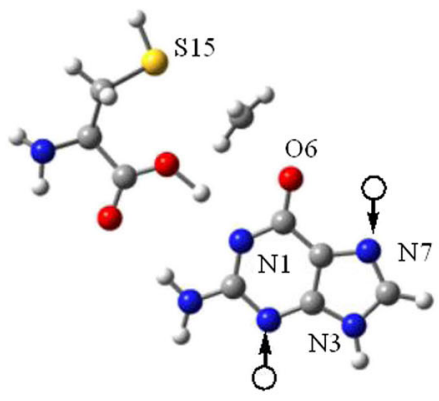

$\mathrm{O} 6 \mathrm{C} 10=1.97$

$\mathrm{S} 15 \mathrm{C} 10=2.49$

O $6 \mathrm{C} 10 \mathrm{~S} 15=172.58$

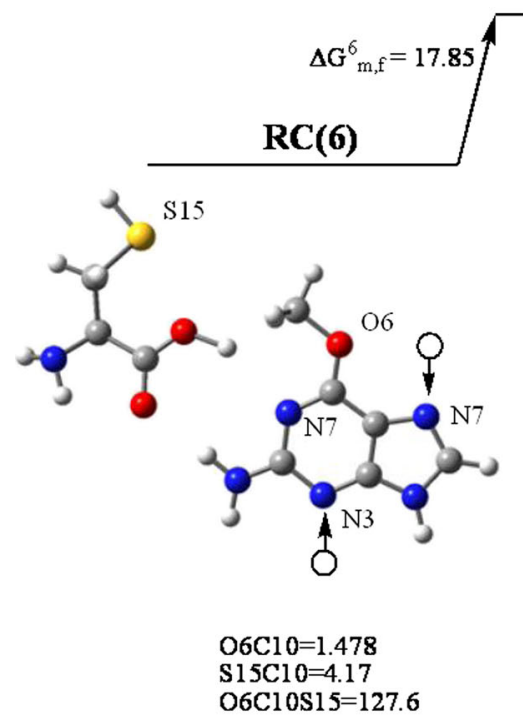

TS(6)
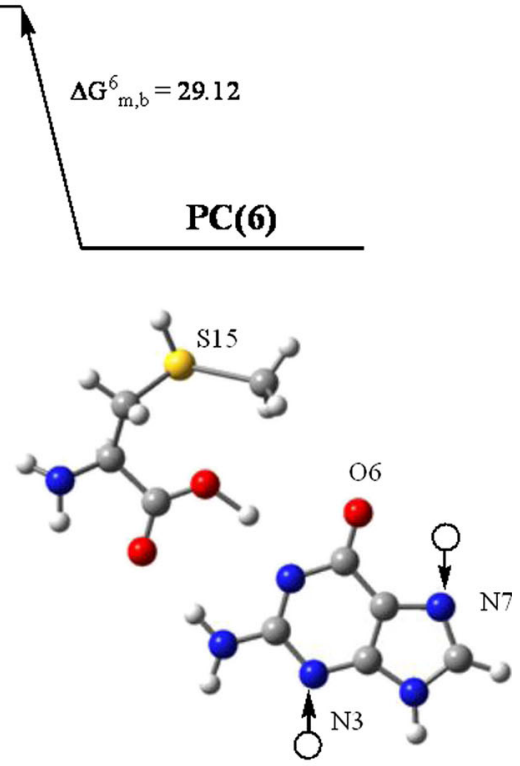

$\mathrm{O} 6 \mathrm{Cl} 0=5.87$

$\mathrm{S} 15 \mathrm{C} 10=1.82$

O6Clos $15=71.63$

Figure 6. Repair of O6mG to guanine by Cys145; two protonated sites are shown by hollow circles. 
Table 4. The barrier energies ( $\Delta \mathrm{E}$ and $\Delta \mathrm{G}$ in $\mathrm{kcal} \mathrm{mol}^{-1}$ ) involved in the repair of the protonated O6mG (at N7 \& N3 site) and Cys 145 at different levels of theory for models 5 and 6.

\begin{tabular}{lccc}
\hline & $\begin{array}{c}\text { B3LYP } \\
6-311++\mathrm{G}^{* *}\end{array}$ & $\begin{array}{c}\text { B3LYP } \\
\text { AUG-cc-pVDZ }\end{array}$ & $\begin{array}{c}\text { MP2 } \\
6-311++\mathrm{G}^{* *}\end{array}$ \\
\hline$\Delta \mathrm{E}_{\mathrm{m}, \mathrm{f}}^{5}$ & $30.57(29.41)$ & $28.34(27.35)$ & $31.72(30.41)$ \\
$\Delta \mathrm{E}_{\mathrm{m}, \mathrm{b}}^{5}$ & $50.66(48.51)$ & $47.77(46.28)$ & $50.67(49.62)$ \\
$\Delta \mathrm{G}_{\mathrm{m}, \mathrm{f}}^{5}$ & $31.19(30.61)$ & $29.68(27.51)$ & $34.13(35.73)$ \\
$\Delta \mathrm{G}_{\mathrm{m}, \mathrm{b}}^{5}$ & $50.24(50.41)$ & $49.93(50.29)$ & $52.83(50.12)$ \\
$\Delta \mathrm{E}_{\mathrm{m}, \mathrm{f}}^{6}$ & $17.85(16.47)$ & $16.13(15.63)$ & $19.92(18.32)$ \\
$\Delta \mathrm{E}_{\mathrm{m}, \mathrm{b}}^{6}$ & $29.12(28.62)$ & $28.25(29.37)$ & $36.22(37.63)$ \\
$\Delta \mathrm{G}_{\mathrm{m}, \mathrm{f}}^{6}$ & $16.57(16.42)$ & $17.52(18.54)$ & $21.32(21.84)$ \\
$\Delta \mathrm{G}_{\mathrm{m}, \mathrm{b}}^{6}$ & $28.73(27.49)$ & $29.30(29.48)$ & $37.28(37.35)$ \\
\hline
\end{tabular}

Energies obtained in aqueous media are given in the parentheses. (m: methyl transfer, f: forward and b: backward)

MP2/6-311++G** levels of theory. Similar results are also obtained for the $\Delta \mathrm{G}_{\mathrm{m}, \mathrm{f}}^{6}$ values (table 4).

The ChelpG charges calculated on the $\mathrm{O} 6 \mathrm{mG}$ and Cys 145 components are equal to 1.87 and -0.02 e, respectively, so the positive charge is strongly localized on $\mathrm{O} 6 \mathrm{mG}$ in $\mathbf{R C}(\mathbf{6})$. In $\mathbf{T S}(\mathbf{6})$, the charges calculated on O6mG, Cys 145 and the methyl group become 1.30, 0.31 and 0.38 e. With a higher positive charge, $\mathrm{O} 6 \mathrm{mG}$ has a higher tendency to transfer the methyl group to Cys 145 component. Finally, the methyl group attaches to Cys145 and completes the repair process in $\mathbf{P C}(\mathbf{6})$. As a result, the energy barrier reduces significantly by protonation of the $\mathrm{N} 7$ and $\mathrm{N} 3$ sites of $\mathrm{O} 6 \mathrm{mG}$.

The energy gap between HOMO and LUMO orbital is equal to 5.44 and $4.92 \mathrm{eV}$ in $\mathbf{R C}(5)$ and $\mathbf{R C}(\mathbf{6})$, respectively. It is expected that the $\mathbf{R C}(\mathbf{6})$ is more reactive than $\mathbf{R C}(\mathbf{5})$.

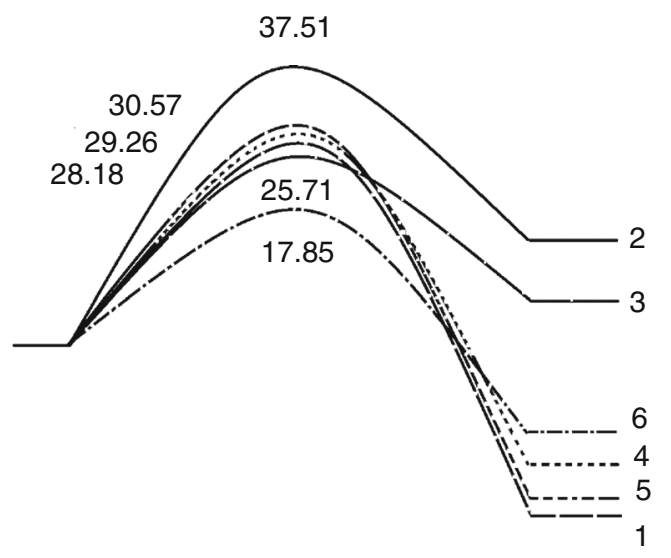

Figure 7. The relative energies in $\mathrm{kcal} \mathrm{mol}^{-1}$ obtained for the methyl transfer at the B3LYP/6-311++G(d,p) level of theory. The numbers $1-6$ correspond to models $1-6$.
The relative energies obtained for the methyl transfer at the B3LYP/6-311++G(d,p) level of theory are shown in figure 7 . The relative energies of products do not correspond to the most stable conformers. They correspond to the conformers obtained from TS structures on the scan process. Proton transfer does not take place in some models, and its barrier energy is lower than methyl transfer for other models. Thus, the methyl transfer would correspond to the rate-limiting step.

\section{Conclusions}

The repair of $06 \mathrm{mG}$ has been investigated by the quantum mechanical calculations with six models in the present work. The most important conclusions are:

1. The proton transfer from Cys 145 to $\mathrm{O} 6 \mathrm{mG}$, as a separate step, diminishes the energy barrier (model 1). This step increases the positive charge on $\mathrm{O} 6 \mathrm{mG}$, decreases the stability of damaged base and facilitates the methyl transfer from $\mathrm{O} 6 \mathrm{mG}$ to Cys145.

2. The energy barrier increases when two water molecules are bridged between $\mathrm{O} 6 \mathrm{mG}$ and Cys145 components and the proton transfer is not considered as a separate step (model 2). But, the barrier decreases substantially, such that it becomes lower than that of model (1) when the proton transfer via bridged water molecule is considered as a separate step (model $\mathbf{3}$ ).

3. Although the change in the barrier $(\Delta \mathrm{E})$ is negligible in the presence of nine additional water molecules located around the O6mG and Cys 145 components, the $\Delta G$ value decreases by about $15 \%$ (model 4).

4. The protonation of the N7 site of O6mG is accompanied by accumulation of positive charge on O6mG helps the methyl transfer from O6mG to Cys145 (model 5).

5. The protonation of the N3 and N7 sites of O6mG induces more positive charge on $\mathrm{O} 6 \mathrm{mG}$ and causes the methyl transfer from $\mathrm{O} 6 \mathrm{mG}$ to Cys145. As a result, the energy barrier decreases due to increase in the number of protonated sites (model 6).

\section{References}

1. Jena N R and Mishra P C 2006 J. Comput. Chem. 28 1321

2. Shukla P K and Mishra P C 2008 J. Phys. Chem. B 112 4779

3. Wyatt M D and Pittman D L 2006 Chem. Res. Toxicol. 191580 
4. Loveless A 1969 Nature 223206

5. Loechler E L, Green C L and Essigmann J M 1984 Proc. Natl. Acad. Sci. USA 816271

6. Mishina Y, Duguid E M and He C 2006 Chem. Rev. 106 215

7. Neeley W L and Essigmann J M 2006 Chem. Res. Toxicol. 19491

8. Burrows C J and Muller J G 1998 Chem. Rev. 98 1109

9. Simons J 2006 Chem. Res. 39772

10. Singer B 1976 Nature 264333

11. Shukla P K and Mishra P C 2010 Theor. Chem. Acc. 125 269

12. Shukla P K, Mishra P C and Suhai S 2007 Chem. Phys. Lett. 449323

13. Mitra S 2007 Mutat. Res. 61064

14. Doak S H, Brüsehafer K and Dudley E 2008 Mutat. Res. 6489

15. Bignami M, O’Driscoll M, Aquilina G, Karran P 2000 Mutat. Res. 46271

16. Kaina B Christmann M, Naumann S and Roos W P 2007 DNA Repair 61079

17. Tubbs J L, Pegg A E and Tainer J A 2007 DNA Repair 6 1100

18. Pegg A E 2000 Mutat. Res. 46283

19. Schroering A G, Kothandapani A, Patrick S M, Kaliyaperumal S, Sharma V P and Williams K J 2009 Cancer Res. 696307

20. Hill J W, Hazra T K Izumi T and Mitra S 2001 Nucleic Acids Res. 29430
21. Xu-Welliver M and Pegg A E 2002 Carcinogenesis 23 823

22. Sedgwick B, Bates P A, Paik J, Jacobs S C and Lindahl T 2007 DNA Repair 6429

23. Shukla P K and Mishra P C 2009 Phys. Chem. Chem. Phys. 118191

24. Qianqian H, Likai D, Jun G, Yongjun L and Chengbu L 2010 J. Phys. Chem. B. 11415296

25. Tiwari S and Mishra P C 2009 J. Mol. Model. 151407

26. Jena1 N R 2011 Phys. Biol. 8046007

27. Jena N R, Shukla P K, Jena H S, Mishra P C and Suhai S 2009 J. Phys. Chem. B 11316285

28. Becke A D 1993 J. Chem. Phys. 985648

29. Lee C, Yang W and Parr R G 1988 Phys. Rev. B 37785

30. Frisch M J et al., 2009 Gaussian 09, Revision A.02; Gaussian Inc. Wallingford CT

31. Mennucci B and Tomasi J 1997 J. Chem. Phys. 1065151

32. Frisch M J, Head-Gordon M and Pople J A 1990 Chem. Phys. Lett. 166275

33. Breneman C M and Wiberg K B 1990 J. Comput. Chem. 11361

34. Reed A E, Curtiss L A and Weinhold F 1988 Chem. Rev. 88899

35. Glendening E D, Reed A E, Carpenter J E and Weinhold F 1990 NBO version 3.1 Theoretical Chemistry Institute. University of Wisconsin. Madison

36. Dobrowolski J C, Rode J E and Sadlej J 2007 Theochem 810129

37. Georgieva P and Himo F 2008 Chem. Phys. Lett. 463 214 